\title{
Synthesis, Evaluation, Modeling and Simulation of Nano-pore NaA Zeolite Membranes
}

\author{
R. Mansoor Kazemimoghadam ${ }^{1 *}$ and Zahra Amiri Rigi ${ }^{2}$ \\ ${ }_{1}^{1}$ Department of Chemical Engineering, Malek-Ashtar University of Technology, Tehran, Iran. \\ ${ }^{2}$ Department of Chemical Engineering, South Tehran Branch, Islamic Azad University, Tehran, Iran.
}

\begin{abstract}
Zeolite membranes have uniform and molecular-sized pores that separate molecules based on the differences in the molecules' adsorption and diffusion properties. Strong electrostatic interaction between ionic sites and water molecules (due to its highly polar nature) makes the zeolite NaA membrane very hydrophilic. Zeolite NaA membranes are thus well suited for the separation of liquid-phase mixtures by pervaporation. In this study, experiments were conducted with various Ethanol-water mixtures (1-20 wt. \%) at $25^{\circ} \mathrm{C}$. Total flux for Ethanol-water mixtures was found to vary from 0.331 to 0.229 $\mathrm{kg} / \mathrm{m}^{2}$.h with increasing Ethanol concentration from 1 to $20 \mathrm{wt} . \%$. Ionic sites of the NaA zeolite matrix play a very important role in water transport through the membrane. These sites act both as water sorption and transport sites. Surface diffusion of water occurs in an activated fashion through these sites. The precise Nano-porous structure of the zeolite cage helps in a partial molecular sieving of the large solvent molecules leading to high separation factors. A comparison between experimental flux and calculated flux using Stephan Maxwell (S.M.) correlation was made and a linear trend was found to exist for water flux through the membrane with Ethanol concentration. A comprehensive model also was proposed for the Ethanol/water pervaporation (PV) by Finite Element Method (FEM). The 2D model was masterfully capable of predicting water concentration distribution within both the membrane and the feed side of the pervaporation membrane module.
\end{abstract}

KEYWORDS: Nano pores; Pervaporation; Ethanol separation; Zeolite NaA membrane; FEM simulation.

(C) 2017 mahendrapublications.com, All rights reserved

\section{INTRODUCTION}

Ethanol is a very important and commonly used solvent in biopharmaceutical and chemical industries. It is widely applied as a disinfectant in medical products, as fuel in rockets and engines and as a feedstock for synthesis of other organic chemicals such as acetic acid, Butanol and ethyl ester [1-3]. Thus, it is very important to treat ethanol wastewaters to separate this valuable material and prevent its wasting.

Separation of Ethanol from its aqueous mixture can be performed through conventional distillation. However, purification of Ethanol solution is very difficult by distillation mainly because it forms an azeotrope with water once it reaches 89.4 mole $\%$ at $78{ }^{\circ} \mathrm{C}$ and atmospheric pressure. Thus, azeotropic distillation must be applied for this purpose. However, azeotropic distillation is more energy demanding than traditional distillation. Besides that, benzene, a highly carcinogenic and toxic substance will be produced in this process, which is considered a major health concern $[4,5]$.

Instead, pervaporation (PV) is an economical filtration technique compared to conventional distillation, especially in processes involving azeotropes, isomers and removal or recovery of trace substances. This is mainly because that only a fraction of the solution that needs to be separated is vaporized in pervaporation. Additionally, high flux rate of PV makes this method an efficient purification procedure resulting in energy cost saving. Table 1 shows the amount of energy demanded by different separation processes in ethanol dehydration. In terms of energy requirement, pervaporation is an obvious choice in Ethanol-water filtration [6-9]. Aside from consuming lower energy, capital cost of PV operation is considerably lower, which makes it again more effective compared to distillation.

PV has attracted great attention not only for its costeffective features, but also for its simplicity and safe operation. In fact, the main tools applied in PV systems are a vacuum pump creating the required driving force and a membrane separating the solution. Furthermore, pervaporation eliminates the use of toxic materials such as benzene and thus is a promising alternative for energy consuming distillation systems in filtering azeotropic mixtures. Hence, relatively mild operating conditions and high effectiveness make PV an appropriate technique for such separations [10-13].

In general, polymeric membranes can be applied for PV dehydration of organic solutions such as Ethanol-water mixture. However, these membranes are not suitable for applications involving harsh chemicals due to the membrane chemical instability. In this regard, recent chemical-and-temperature resistant hydrophilic ceramic membranes have been developed, making it possible to overcome the limitations of polymeric membranes [14-16]. Since zeolites are most hydrophilic and have well-defined open crystal structures with a pore size of several angstroms, they are another candidate for the pervaporation dehydration of highly concentrated Ethanol aqueous solution. These unique structural characteristics and hydrophilic nature have rendered zeolite materials possessing pronounced molecular sieving effect and

*Corresponding Author: mzkazemi@gmail.com

Received: 10.10.2017 Accepted: 15.11.2017_ Published on: 12.12.2017 
selective adsorption capability (i.e., appreciated separation performance). Therefore, zeolites can be extensively used in removal of volatile organic chemicals from air streams, separation of isomers and mixtures of gases, shapeselective catalysis and ion exchange. Zeolitic membranes offer several advantages over polymeric ones. Firstly, they do not swell significantly compared to the polymeric membranes. Secondly, they have uniform molecular-sized pores that provide differential transport rates and molecular sieve effects. Thirdly, the zeolitic structures are more chemically stable and tolerant to severe separation conditions such as strong solvents or low $\mathrm{pH}$ solutions. Last but not least, zeolites are thermally stable up to high temperatures of $1000^{\circ} \mathrm{C}[17,18]$.

In pervaporation, the feed mixture is contacted with a perm-selective nonporous membrane. Separation is generally explained by the steps of sorption into, diffusion through and desorption from the membrane. The latter is usually considered fast and taking place at equilibrium while diffusion is kinetically controlled and the slowest step of the process. Permeation is dependent on the sorption and diffusion steps. The driving force for the separation is created by maintaining a pressure lower than the saturation pressure on the permeate side of the membrane. The mechanism of filtration is usually described in terms of sorption-diffusion processes [19-22]. A great deal still remains to be known about the transport mechanisms of various species through zeolite membranes. The transport mechanism of aqueous species through zeolitic materials is more complex than through polymeric membranes, since it can involve movement through both molecularly selective zeolite micro crystals as well as less selective interstitial regions. This produces a complex morphology and transport situation.

Extensive studies have been conducted for mass transfer modeling of PV systems [23-30]. Recently Rezakazemi et al. (2011) proposed a model for PV separation of water/ethylene glycol solution based on solving equations of mass and momentum conservation (Navier-Stokes equations) with Finite Element Method (FEM) [25]. Effect of temperature and velocity was investigated in their research and their results were in good agreement with experimental data. After Rezakazemi et al., Moulik et al. (2015) used the same approach and developed a steady state model to predict mass transfer of MMH and UDMH solutions by pervaporation [23]. Their results were also in reasonable accordance with empirical data. Nonetheless, their model was not comprehensive, since they only modeled the membrane section of the module. The effect of dimensional factors relating to the geometry of the system is also neglected in their study.

So far, few attempts have been done to simulate Ethanol/water pervaporation. This paper focuses on purification of Ethanol-water mixtures using hydrophilic zeolite membranes in pervaporation process. The objective of this study was to develop effective models for providing a deep insight into the dehydration of Ethanol/water mixtures with PV technology. A comparison between experimental flux and calculated flux using S.M. Correlation was made and a linear trend was found to exist for water flux through the membrane with Ethanol concentration. Impact of the differences in the transport mechanisms on PV flux and selectivity was also discussed. A mathematical model based on CFD technique was finally proposed and the effect of different membrane's dimensions, initial Ethanol concentration and feed flow rates on water concentration was investigated to find the optimum operation condition. Proposed model was distinctively capable of predicting concentration distribution in both membranes, feed sub-domains, and provided a perfect understanding of the effect of various operating condition on the membrane performance.

\section{ZEOLITE STRUCTURE AND TRANSPORT MECHANISMS}

The hydrophilic membranes used in this research were composite zeolite NaA membranes. The membranes were basically made of an active $\mathrm{NaA}$ layer, deposited on a ceramic porous mullite support. The active NaA layer is responsible for high separation factors achieved in PV of Ethanol mixtures. The structure of zeolite $\mathrm{NaA}$ is shown in Fig. 1.

As shown in the figure, the aluminosilicate framework of zeolite $\mathrm{NaA}$ is generated by placing truncated octahedrons (b-cage) at eight corners of a cube and each edge of the cube is formed by joining two b-cages by a D4R linkage. Each b-cage encloses a cavity with a free diameter of 0.66 $\mathrm{nm}$ and each unit cell encloses a larger cavity (a-cage) enclosing a free diameter of $1.14 \mathrm{~nm}$. There are two interconnecting, three-dimensional channels in zeolite $\mathrm{NaA}$ : (i) connected a-cages, $1.14 \mathrm{~nm}$ in diameter, separated by $0.42 \mathrm{~nm}$ apertures, (ii) b-cages, alternating with a-cages separated by $0.22 \mathrm{~nm}$ apertures. Thus, molecules smaller than $0.42 \mathrm{~nm}$ in diameter can diffuse easily through the nanopores of the zeolite. Moreover, position of sodium ions in unit cells is important since these ions act as the sites for water sorption and transport through the membrane. For a typical zeolite, a unit cell having the composition $\mathrm{Na}_{12} \mathrm{Al}_{12} \mathrm{Si}_{12} \mathrm{O}_{48} .27 \mathrm{H}_{2} \mathrm{O}$, eight (out of 12) sodium ions are located inside a-cage and four ions are located in b-cages. Transport of solvent species (mainly water) through the zeolite matrix comprises of three steps: (i) strong adsorption of the species into a cage from feed side, (ii) surface diffusion of the species from cage to cage and (iii) vaporization of the species to permeate side. Normally, any physical adsorption process includes both van der Waals dispersion-repulsion forces and electrostatic forces comprising of polarization, dipole and quadruple interactions. However, since the zeolites have an ionic structure, the electrostatic forces become very large in adsorption of polar molecules like $\mathrm{H}_{2} \mathrm{O}$. This effect is manifested in the fact that heat of adsorption of water into zeolitic adsorbents is unusually high $(25-30 \mathrm{kcal} / \mathrm{mole})$. Researchers have extended the dusty-gas model approach to describe the surface-diffusion of molecules into a zeolite surface. The vacant sites are assumed to be the $(n+1)$ pseudo-species in the system and S.M. Equation is used to correlate surface chemical potential gradient to flux of the various species, as shown in Eq. (1):

\section{Kazemimoghadam et al.,}




$$
-\nabla \mu_{i}=R T \sum_{k=1}^{n} \theta_{k} \frac{\left(v_{i}-v_{n+1}\right)}{D_{i k}^{g}}+R T \theta_{n+1} \frac{\left(v_{i}-v_{n+1}\right)}{D_{i n+1}^{g}}, i=1,2_{z} \ldots
$$

For two components denoted by 1 and 2, diffusing in a zeolite pore where the vacant sites are represented by $v$, individual component equations can be written as shown in Eqs. (2) And (3) (velocity of the sites $v_{v}$ is equal to 0 ). It is also conventional to define surface diffusivity $D_{i v}^{g}$ as the ratio of $D_{i n+1}^{g}$ and $\theta_{n+1}$.

$-\frac{\nabla \mu_{1}}{R T}=\left[\frac{\theta_{2}\left(v_{1}-v_{2}\right)}{D_{12}^{S}}+\frac{v_{1}}{D_{1 v}^{g}}\right]$

$-\frac{\nabla \mu_{2}}{R T}=\left[\frac{\theta_{1}\left(v_{2}-v_{1}\right)}{D_{21}^{g}}+\frac{v_{2}}{D_{2 V}^{g}}\right]$

Surface flux of each species through the zeolite pore is represented by Eqs. (4) And (5), where $\rho_{p}$ is density of the zeolite, $\varepsilon$ is porosity, $q_{g a t}^{i}$ is maximum possible sorption of component $i$ into the zeolite, $\theta_{i}$ is site occupancy of species $i$ and $v_{\hat{i}}$ is velocity of component $i$ through the pores.

$J_{1}^{g}=\rho_{p} \varepsilon q_{s a t}^{1} \theta_{1} v_{1}$

$I_{2}^{g}=\rho_{p} \varepsilon q_{g a t}^{2} \theta_{2} v_{2}$

By assuming that there is no counter diffusion or coupling between the two species ( $D_{12}^{s}$ and $\left.D_{21}^{s} \rightarrow \infty\right)$, Eqs. (2) and

(3) can be further simplified to Eqs. (6) and (7):

$$
\begin{aligned}
& -\frac{\nabla \mu_{1}}{R T}=\frac{J_{1}^{\Xi}}{\rho_{p} \varepsilon q_{\varepsilon a t}^{1} \theta_{1} D_{1 V}^{g}} \\
& -\frac{\nabla \mu_{2}}{R T}=\frac{J_{2}^{\Xi}}{\rho_{p} \varepsilon q_{\varepsilon a t}^{2} \theta_{2} D_{2 V}^{g}}
\end{aligned}
$$

From basic thermodynamics, chemical potential gradients $\nabla \mu_{1}$ and $\nabla \mu_{2}$ can be represented as gradients of the site occupancy of each species by the following equations:

$$
\begin{aligned}
& -\frac{\theta_{1} \nabla \mu_{1}}{R T}=\theta_{1} \frac{\partial \ln a_{1}}{\partial \theta_{1}} \frac{d \theta_{1}}{d z}+\theta_{1} \frac{\partial \ln a_{1}}{\partial \theta_{2}} \frac{d \theta_{2}}{d z} \\
& -\frac{\theta_{2} \nabla \mu_{2}}{R T}=\theta_{2} \frac{\partial \ln a_{2}}{\partial \theta_{2}} \frac{d \theta_{2}}{d z}+\theta_{2} \frac{\partial \ln a_{2}}{\partial \theta_{1}} \frac{d \theta_{1}}{d z}
\end{aligned}
$$

With equating Eqs. (6) and (7) with Eqs. (8) and (9), respectively, the following equations will be obtained:

$$
\begin{aligned}
& l_{1}^{g}=-\rho_{p} \varepsilon q_{g a t}^{1} D_{1 V}^{g}\left[\theta_{1} \frac{\partial \ln a_{1}}{\partial \theta_{1}} \frac{d \theta_{1}}{d z}+\theta_{1} \frac{\partial \ln a_{1}}{\partial \theta_{2}} \frac{d \theta_{2}}{d z}\right] \\
& h_{2}^{g}=-\rho_{p} \varepsilon q_{g a t}^{2} D_{2 V}^{g}\left[\theta_{2} \frac{\partial \ln a_{2}}{\partial \theta_{2}} \frac{d \theta_{2}}{d z}+\theta_{2} \frac{\partial \ln a_{2}}{\partial \theta_{1}} \frac{d \theta_{1}}{d z}\right]
\end{aligned}
$$

The above two equations describe flux of each component through the zeolite pore. Nature of the functions $\left(\frac{\partial \ln a_{1}}{\partial \theta_{1}}\right),\left(\frac{\partial \ln a_{1}}{\partial \theta_{2}}\right),\left(\frac{\partial \ln a_{2}}{\partial \theta_{1}}\right)$ and $\left(\frac{\partial \ln a_{2}}{\partial \theta_{2}}\right)$ depends on the nature of the sorption isotherm of each compound into the zeolite. Diffusivities $D_{1 V}^{S}$ and $D_{2 V}^{S}$ are also dependent on the site occupancies, $\theta_{1}$ and $\theta_{2}$. Thus, to be able to model flux of each component through the zeolite cages, knowledge of both diffusion and sorption characteristics is essential. For zeolites with narrow pores (as in the case of zeolite $\mathrm{NaA}$ ), single file diffusion can be assumed to take place. In the case of single file diffusion, only one molecule can diffuse through the cross-section of the pore at any given time. The S.M. surface diffusivity $\left(D_{1 V}^{g}\right)$ depends linearly on the vacant sites $\theta_{V}$ as shown below:

$D_{1 V}^{g}=D_{1 V}^{g}(0) \theta_{V}$

A Langmuirian type of sorption isotherm (for pure water into zeolite sites) to predict activity $\left(a_{w}\right)$ in the zeolite for a given site, occupancy $\left(\theta_{W}\right)$ can be assumed:

$a_{W}=\frac{A \theta_{W}}{1-\theta_{W}}$

For pure water-zeolite system, there is no second component and Eqs. (11)-(13) can be used to obtain the pure water flux equation as:

$h_{w}^{g}=\rho \varepsilon q_{s a t}^{w} D_{w V}^{g}(0) \frac{d \theta_{w}}{d z}$

Integrating the above equation between the limits $\mathrm{z}=0$, $\mathrm{q}_{\mathrm{w}}=\mathrm{q}_{\mathrm{w}, \mathrm{f}}$ and $\mathrm{z}=\delta, \theta_{\mathrm{w}}=\theta_{\mathrm{w} . \mathrm{P}}$ :

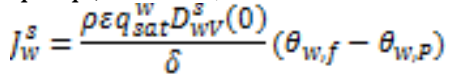

Multiplying $q_{s a t}^{W}$ by the terms in the bracket, the final flux equation is:

$h_{w}^{s}=\frac{\rho \varepsilon D_{W V}^{s}(0)}{\delta}\left(q_{w f}-q_{w p}\right)$

Where $D_{W, f}^{W}$ and $D_{w p}^{W}$ are the sorbet quantities of water into the zeolite at the feed and the permeate interfaces. The above equation is based on the premise that transport of various species through a dense zeolite membrane follows the solution-diffusion mechanism. It should be mentioned that zeolite membranes obey a sorption-diffusion model like polymeric membranes. However, the ionic interactions are stronger in the case of zeolite membranes. The ionic interactions affect both the sorption and the diffusion of water into the membrane. For the zeolite membranes, a solution-diffusion mechanism can be envisioned wherein the water molecules first adsorb preferentially at the cage mouth and then diffuse across the active layer. For solvent molecules, however, the partial molecular sieving effects and permeation through non-zeolitic pores may also need to be considered. Therefore, a permeability parameter $\mathrm{K}_{\mathrm{w}}$ can also be defined for water permeation through zeolite membranes in a similar manner as for polymeric membranes. The parameter is a lumped parameter comprising of the water diffusivity through the membrane, its sorption onto the membrane material and the

\section{Kazemimoghadam et al.,}


membrane thickness. The above equation assumes that the permeability parameter remains constant under various feed concentrations and temperatures. However, this is not always true, especially in the case of polymeric membranes. For example, hydrophilic polymeric membranes tend to swell substantially in the presence of high water concentrations causing substantial changes in the permeability parameter of the polymer. The above model is a comprehensive modeling approach and gives helpful insights into the actual transport process within Nanopores of the zeolite [31-33].

\section{EXPERIMENTAL}

\subsection{Support preparation}

In this research, mullite supports were prepared from kaolin clay. Kaolin is thermally converted to mullite via high temperature calcinations. The reaction takes place when kaolin is utilized as the sole source of silica and alumina. The reaction can be represented by the following equation:

$3\left(\mathrm{Al}_{2} \mathrm{O}_{3} \cdot 2 \mathrm{SiO}_{2}\right) \longrightarrow 3 \mathrm{Al}_{2} \mathrm{O}_{3} \cdot 2 \mathrm{SiO}_{2}+4 \mathrm{SiO}_{2}$

Free silica $\left(4 \mathrm{SiO}_{2}\right)$ is generated as a result of this conversion. The free silica was leached out and then porous mullite bodies were prepared.

Kaolin (SL-KAD grade) was supplied by WBB cooperation, England. Analysis of the kaolin is listed in Table 2. Cylindrical shaped (tubular) bodies have been conveniently made by extruding a mixture of about $75-67 \%$ kaolin and $25-33 \%$ distilled water. Suitable calcinations temperatures and periods are those at which kaolin converts to mullite and free silica. Good results were achieved by calcinations for about $3 \mathrm{~h}$ at temperatures of about $1250^{\circ} \mathrm{C}$ [34-36].

Free silica was removed from the calcined bodies after leaching by strong alkali solutions. Removal of the silica caused meso-porous tubular supports with very high porosity. Free silica removal was carried out using aqueous solutions containing $20 \%$ by weight $\mathrm{NaOH}$ at a temperature of $80{ }^{\circ} \mathrm{C}$ for $5 \mathrm{~h}$. In order to remove all the remaining $\mathrm{NaOH}$ supports were rinsed using huge amount of hot distilled water for a long time. Porosity of the supports before leaching was $24.3 \%$ while after treatment it increased to $49 \%$. Flux of the supports before and after free silica removal at 1 bar and $20{ }^{\circ} \mathrm{C}$ was $6 \mathrm{~kg} / \mathrm{m}^{2} \mathrm{~h}$ and $10 \mathrm{~kg} / \mathrm{m}^{2} \mathrm{~h}$, respectively. Porosity of the supports was measured by water absorption method. Phase identification was performed by X-ray diffraction with $\mathrm{CuK}_{\alpha}$ radiation.

\subsection{ZEOLITE MEMBRANE SYNTHESIS}

\subsubsection{Coating of the support with seeds}

Adding seed crystals to this crystallization system resulted in increased crystallization rate. The enhanced rate might be due to simply increasing the rate at which solute is integrated into the solid phase from solution due to the increased available surface area, but also might be the result of enhanced nucleation of the new crystals. The secondary nucleation mechanism referred to as initial breeding results from microcrystalline dust being washed off seed crystal surfaces in a new synthesis batch. These microcrystalline fragments grew to observable sizes, and resulted in greatly enhanced crystallization rates due to remarkably increased crystal surface area compared to the unseeded system. Consequently, it is expected that addition of seed crystals to a synthesis system will introduce submicron sized crystallites into the system that will serve as nuclei.

As described above, porous mullite tubes (homemade) were used as the support. The external surface of the supports was polished with 600-grit sandpapers, and then the support was washed and cleaned with distilled water in a microwave heater for $5 \mathrm{~min}$ to remove loose particles created during polishing. Then, supports were dried at $100{ }^{\circ} \mathrm{C}$ for $3 \mathrm{~h}$.

In order to form a thin and uniform zeolite membrane on the mullite support, the nucleation seeds should be small and uniform in size. In order to inhibit the formation of the zeolites into the support pores, the seeds should not penetrate into the pores. The high purity nucleation seeds were synthesized by hydrothermal method. Size of the seeds was about $2 \mu \mathrm{m}$. The seeds must be dispersed homogeneously on the support surface and the amount of seeds on the support surface must not be too much. Otherwise, the synthesized zeolite membrane is heterogeneous or too thick.

The seeded supports were prepared by dipping the mullite supports in an $8 \% \mathrm{NaA}$ zeolite suspension in a single step. The $8 \% \mathrm{NaA}$ zeolite suspension was prepared by mixing $8 \mathrm{~g}$ $\mathrm{NaA}$ zeolite in $92 \mathrm{ml}$ distilled water. After dipping procedure, the supports were dried at $100{ }^{\circ} \mathrm{C}$ for $3 \mathrm{~h}$.

\subsubsection{Nano-pore NaA zeolite synthesis}

Thin zeolite $\mathrm{NaA}$ membrane layers were grown hydro thermally over the external surface of the porous supports. Synthesis solution was prepared by mixing aluminates and silicate solutions. $\mathrm{NaOH}$ (4.87 g) was dissolved in $76 \mathrm{ml}$ of distilled water. The solution was divided into two equal volumes and kept in polypropylene bottles. Aluminates solution was prepared by adding $6.23 \mathrm{~g}$ sodium aluminates (Aldrich, $50-56 \% \mathrm{Al}_{2} \mathrm{O}_{3}$ ) to one part of the $\mathrm{NaOH}$ solution. It was mixed until cleared. Silicate solution was prepared by adding $16.57 \mathrm{~g}$ sodium silicate (Merck, 25-28\% $\mathrm{SiO}_{2}$ ) to another part of the $\mathrm{NaOH}$ solution. Silicate solution was then poured into aluminates solution and well mixed until a thick homogenized gel was formed. Composition of the homogeneous solution of zeolite $\mathrm{NaA}$ is represented by the following molar ratio: $1.926 \mathrm{SiO}_{2}: \mathrm{Al}_{2} \mathrm{O}_{3}: 3.165 \mathrm{Na}_{2} \mathrm{O}: 128$ $\mathrm{H}_{2} \mathrm{O}[37,38]$.

Two ends of the supports were closed with rubber caps to avoid any precipitation of the zeolite crystals on internal surface of the supports during membrane synthesis. The seeded supports were placed vertically in a Teflon autoclave. The solution was carefully poured in the autoclave and then the autoclave was sealed. Crystallization was carried out in an oven at temperatures of 70,90, 100, 110 and $140{ }^{\circ} \mathrm{C}$ for $1,2.5,3,4$ and $5.5 \mathrm{~h}$. Then, the samples were taken and the synthesized membranes were washed several times with distilled water. The samples were then dried at room temperature for $12 \mathrm{~h}$ in air. Some samples were coated two and three times to study effect of number of coating.

\section{Kazemimoghadam et al.,}




\subsection{Pervaporation experiments}

A PV experimental set up was used to evaluate successful fabrication of $\mathrm{NaA}$ zeolite membranes. PV experiments were carried out using a standard PV apparatus. Feed solution, preheated to a constant temperature, was introduced to the outer side of the zeolite membrane in the PV cell. The downstream pressure was maintained at 133 Pa throughout the operation. The zeolite membranes were used for dehydration of aqueous Ethanol mixtures. The Ethanol mixtures $(1,5,10,15$ and 20 wt. \%) were used and experiments were carried out at room temperature $\left(25^{\circ} \mathrm{C}\right)$ within a period of 30-60 min. Permeate concentrations were measured using GC (TCD detector, Varian 3400, carrier gas: hydrogen, column: polyethylene glycol, sample size: 5 micron, column and detector temperatures: $120-150$ ${ }^{\circ} \mathrm{C}$, detector flow rate: $15 \mathrm{ml} / \mathrm{min}$, carrier flow: $5 \mathrm{ml} / \mathrm{min}$, column pressure: $1.6 \mathrm{kPa}, \mathrm{GC}$ input pressure: $20 \mathrm{kPa}$ ). Performance of PV was evaluated using values of total flux $\left(\mathrm{kg} / \mathrm{m}^{2} . \mathrm{h}\right)$ and separation factor (dimensionless). Typical experimental setup was employed as presented in Fig. 2. While PV system was steady state (after $20 \mathrm{~min}$ ), we measured weight of permeate after 30 min operation then flux was calculated (area of zeolite membrane is $44 \mathrm{~cm}^{2}$ ). The change in feed concentration due to permeation was negligible because the amount of permeate was small compared to total liquid volume in the system [37-39].

The phases Mullite, Cristobalite and $\mathrm{SiO}_{2}$ identification was performed by XRD (Philips PW1710, Philips Co., Netherlands) with CuK $\alpha$ radiation. Morphology of the support and the membrane was examined by SEM (JEM1200 or JEM-5600LV equipped with an Oxford ISIS-300 Xray disperse spectroscopy (EDS)).

\subsection{Water sorption experiments}

The sorption experiments were performed using zeolite powder (200-mesh size). The zeolite powder in the presence of pure water forms a paste and it is very difficult to distinguish between the 'sorbet water' and the 'interparticle water'. Thus, any sorption data based on gravimetric studies is not expected to be accurate. An indirect and more accurate method was employed to determine the pure water sorption of the zeolite powder. The zeolite powder was weighted and the powder was well mixed with a measured volume of the dilute Ethanol mixture (1, 5, 10, 15 and 20 wt. \%). Equilibrium was established after 18-24 h. After the equilibrium, the mixtures were pressure filtered using a syringe. The water content was accurately measured. It was assumed that at such low Ethanol concentrations, sorption of Ethanol into the zeolite powder is negligible.

\section{FEM simulation}

Fig. 3 represents the schematic diagram of the model domain used in the simulation. Feed solution containing a mixture of 1-20 wt. \% Ethanol flows tangentially through the upper side of the membrane system $(\mathrm{z}=0)$. The feed exits at $\mathrm{z}=\mathrm{L}$ (membrane length) and recirculates inside the system.

The main assumptions to develop the numerical simulation are as follows:
* Steady state and isothermal conditions.

* No chemical reaction occurs in feed stream.

* Feed solution flows only in the z direction.

* Laminar feed flow in the membrane system.

* Thermodynamic equilibrium considered at the interface of feed and membrane.

* Small amount of Ethanol permeates through the membrane.

* Mass transfer resistance of the support layer was assumed to be negligible.

* Fouling and concentration polarization effects on the PV of Ethanol/water solution are negligible.

* The fluid is incompressible.

* Feed viscosity is constant.

Although the diffusive mass transfer in the direction of flow ( $\mathrm{z}$ direction) is small due to the convective flux in this direction, it is not neglected compared to diffusive mass transfer in the $r$ direction. Therefore, axial and radial diffusions inside the membrane and feed phase are considered in the continuity equations. Moreover, the small permeation of Ethanol through the membrane is considered in the simulation by applying selectivity equation (Eq. (18)). The penetration of Ethanol through the selective membrane is described by the following equation:

$$
\mathrm{S}=\frac{\mathrm{X}_{\text {Ethanol }}}{\mathrm{X}_{\text {water }}} \times \frac{\mathrm{Y}_{\text {water }}}{\text { YEthanol }}
$$

The concentration of Ethanol in the permeate side (yEthanol) must be determined by trial and error method. In this method, an initial value for $y_{\text {Ethanol }}$ is guessed. Then the water concentration in the permeate side will be calculated using model equations. This calculated value then must be compared with the guessed value. If the difference between the old and new values is less than a determined error, the guessed Ethanol concentration is considered as the correct concentration. Otherwise, another guess must be made for yEthanol.

Mass transport in the membrane system is described using continuity equation. The following equation presents the differential form of this equation [40]:

$$
\frac{\partial C_{\mathrm{w}}}{\partial \mathrm{t}}+\nabla \cdot\left(-\mathrm{D}_{\mathrm{w}} \nabla \mathrm{C}_{\mathrm{w}}+\mathrm{U}_{\cdot} \mathrm{C}_{\mathrm{w}}\right)=\mathrm{R}
$$

Where $C_{w}$ denotes water concentration $\left(\mathrm{mol} / \mathrm{m}^{3}\right), D_{w}$ denotes water diffusion coefficient $\left(\mathrm{m}^{2} / \mathrm{s}\right)$, U denotes the velocity vector $(\mathrm{m} / \mathrm{s})$ and $R$ denotes the reaction term $\left(\mathrm{mol} / \mathrm{m}^{3} \mathrm{~s}\right)$. Since no chemical reactions takes place in the Ethanol/water PV, the reaction term is zero. Continuity equation was defined and solved in COMSOL Multiphysics 5.2 by adding a "transport of diluted species" physic to the model domain. Velocity distribution was obtained by solving Navier-Stokes equations for momentum balance simultaneously with continuity equation in the feed side. This was done by adding a "laminar flow" physic to the whole model in COMSOL Multiphysics 5.2. The following equation describes the momentum conservation equation [40]:

\section{Kazemimoghadam et al.,}




$$
\begin{aligned}
& \mathrm{p} \frac{\partial \mathrm{u}}{\partial \mathrm{t}}+\mathrm{p}\left(\mathrm{u}_{\mathrm{v}} \nabla\right) \mathrm{u}=\nabla_{\mathrm{x}}\left[-\mathrm{P}+\mu\left(\overline{\mathrm{u}}+(\overline{\mathrm{u}})^{\mathrm{T}}\right)\right]+F_{\mathrm{b}} \\
& \nabla \cdot(\mathrm{u})=0
\end{aligned}
$$

Where u denotes z-component of the velocity vector $(\mathrm{m} / \mathrm{s})$, $\rho$ denotes feed density $\left(\mathrm{kg} / \mathrm{m}^{3}\right)$, $\mathrm{P}$ denotes pressure $(\mathrm{Pa}), \mu$ denotes feed viscosity (Pa.s) and $\mathrm{F}_{\mathrm{b}}$ denotes a body force $(\mathrm{N})$.

\subsection{Feed phase simulation}

By applying mentioned assumptions to the Eq. (19), steady state form of the continuity equation for water mass transport in the feed side is obtained:

$-\frac{1}{\mathrm{r}} \frac{\partial}{\partial \mathrm{r}}\left(\mathrm{D}_{\mathrm{w}} \mathrm{r} \frac{\partial \mathrm{C}_{\mathrm{w}-\mathrm{r}}}{\partial \mathrm{r}}\right)-\frac{\partial}{\partial \mathrm{z}}\left(\mathrm{D}_{\mathrm{w}} \frac{\partial \mathrm{C}_{\mathrm{w}-\mathrm{f}}}{\partial \mathrm{z}}\right)+\mathrm{u} \frac{\partial \mathrm{C}_{\mathrm{w}-\mathrm{f}}}{\partial \mathrm{z}}=0$

The simplified form of the momentum transport equations considering above assumptions will be as follows:

$$
\begin{aligned}
& \mathrm{P}\left(\mathrm{u} \frac{\partial \mathrm{u}}{\partial \mathrm{z}}\right)-\frac{1}{\mathrm{r}} \frac{\partial}{\partial \mathrm{r}}\left(\mathrm{r} \mu \frac{\partial \mathrm{u}}{\partial \mathrm{r}}\right)-\frac{\partial}{\partial \mathrm{z}}\left(\mu \frac{\partial \mathrm{u}}{\partial \mathrm{z}}\right)=-\frac{\partial \mathrm{P}}{\partial \mathrm{z}} \\
& \frac{\partial \mathrm{u}}{\partial \mathrm{z}}=0
\end{aligned}
$$

$\mathrm{r}$ and $\mathrm{z}$ denote radial and axial coordinates, respectively.

The initial conditions for mass and momentum conservation equations are as below:

at $\mathrm{t}=0, \mathrm{C}_{\mathrm{w}-\mathrm{f}}=\mathrm{C}_{0, \mathrm{w}}$ and $\mathrm{u}=\mathrm{u}_{0}$

Where $\mathrm{C}_{\mathrm{w}-\mathrm{f}}$ is water concentration in feed phase, $\mathrm{C}_{0, \mathrm{w}}$ is its initial value and $u_{0}$ is the initial velocity of the feed flow.

The boundary conditions for mass conservation equations in the feed phase are as follows:

at $\mathrm{z}=\mathrm{L}$, Outflow condition

at $\mathrm{z}=0, \mathrm{C}_{\mathrm{w}-\mathrm{f}}=\mathrm{C}_{0, \mathrm{w}}$ (Inlet boundary)

at $r=R_{3}, \frac{\partial C_{W-r}}{\partial z}=0$ (No flux condition)

At the interface of the membrane-feed, the equilibrium condition is assumed:

at $\mathrm{r}=\mathrm{R}_{2}, \mathrm{C}_{\mathrm{W}-\mathrm{f}}=\frac{\mathrm{L}_{\mathrm{W}-\mathrm{fr}}}{\mathrm{n}}$

In which $\mathrm{C}_{\mathrm{w}-\mathrm{m}}$ is water concentration in membrane section and $\mathrm{n}$ is partition coefficient obtained from selectivity equation as follows: $\mathrm{n}=\frac{\text { YEmanol }_{\text {Emal }}}{\mathrm{x}_{\text {Emanol }}} \times \mathrm{S}=\frac{\mathrm{C}_{\mathrm{W}-\mathrm{rit}}}{\mathrm{C}_{\mathrm{W}-\mathrm{r}}}$

As mentioned earlier, permeate concentration of Ethanol must be obtained using trial and error method and then is placed in the above equation.

The boundary conditions for momentum transfer equations are as follows:

at $\mathrm{z}=0, \mathrm{u}=\mathrm{u}_{0}$, (Inlet boundary)

At the outlet, the pressure is atmospheric pressure:

at $\mathrm{z}=\mathrm{L}, \mathrm{P}=\mathrm{P}$ atm, (Atmospheric pressure)

At $r=R_{2}$ and $R_{3}, u=0$ (No slip condition)

\subsection{Membrane phase simulation}

Mass transport of water in the membrane is controlled only by diffusion mechanism. Therefore, the steady state continuity equation for water can be written as:

$-\frac{1}{\mathrm{r}} \frac{\partial}{\partial \mathrm{r}}\left(D_{\mathrm{m}} \mathrm{r} \frac{\partial \mathrm{C}_{\mathrm{W}-\mathrm{m}}}{\partial \mathrm{r}}\right)-\frac{\partial}{\partial z}\left(D_{\mathrm{m}} \frac{\partial \mathrm{C}_{\mathrm{W}-\mathrm{m}}}{\partial \mathrm{z}}\right)=0$

where $D_{m}$ is water diffusion coefficient in membrane $\left(\mathrm{m}^{2} / \mathrm{s}\right)$.

Membrane phase boundary conditions are given as:

at $\mathrm{r}=\mathrm{R}_{2}, \mathrm{C}_{\mathrm{W}-\mathrm{m}}=\mathrm{n} \times \mathrm{C}_{\mathrm{W}-1}$ (Equilibrium condition)

at $\mathrm{r}=\mathrm{R}_{1}, \mathrm{C}_{\mathrm{w}-\mathrm{m}}=0$ (Dry membrane condition)

at $\mathrm{z}=0$ and $\mathrm{z}=\mathrm{L}, \frac{\partial \mathrm{C}_{\mathrm{W}-\mathrm{m}}}{\partial \mathrm{z}}=0$ (No flux condition)

At the permeate-membrane interface, water concentration assumed to be zero due to the vacuum applied on this boundary.

\subsection{Numerical solution of the conservation equations}

Set of model equations, including mass and momentum transfer equations in the membrane module along with suitable boundary conditions was solved using COMSOL Multiphysics software version 5.2. Finite element method (FEM) is applied by this software to solve conservation equations numerically. Previous simulations of membrane separation processes using FEM showed that this method was an accurate, valid and powerful technique for solving mass and momentum equations [23,25,29]. The computational time for solving the equations was about 2 minutes. "Extra fine" mesh was used in the simulation, which consisted of 66007 domain elements and 1940 boundary elements. Fig. 4 represents the meshes created by COMSOL Multiphysics ${ }^{\circledR} 5.2$ software. Due to the considerable difference between $\mathrm{z}$ and $\mathrm{r}$ dimensions, $\mathrm{a}$ scaling factor equal to 6 was used in the $\mathrm{z}$ direction.

\section{Kazemimoghadam et al.,}


Therefore, the results were reported in dimensionless length.

\section{RESULT AND DISCUSSION 4.1. Effect of hydrothermal conditions on membrane formation and performance}

Temperature and time have a positive influence on the zeolite formation process, which occurs over a considerable range of temperatures. A rise in temperature will increase both the nucleation rate and the linear growth rate. Hence, the crystallinity of the samples normally increases in time. As far as time is concerned, zeolite synthesis is governed by the occurrence of successive phase transformations. The thermodynamically least favorable phase will crystallize first and will be successively replaced in time by more stable phases. The best example is the crystallization sequence of amorphous $\rightarrow \mathrm{NaA} \rightarrow \mathrm{HS}$.

The temperature, however, can also influence the type of product that has to be crystallized. A rise in temperature leads to the crystallization of more dense products as the fraction of water in the liquid phase, which has to stabilize the porous products by filling the pores, will drop. Therefore, the existence of an upper limit for the formation of zeolites is to be expected. The use of nonvolatile pore space occupying (filling) species would, in principle, allow a high-temperature synthesis of open, porous structures. Temperature can obviously affect the rate of nucleation and crystal growth.

The linear rates of crystal growth and rates of nucleation both increase with rising temperatures.

To study effect of crystallization time and temperature on $\mathrm{NaA}$ zeolite membrane performance, the membranes were synthesized at different temperatures $(70,90,100,110$, and $\left.140{ }^{\circ} \mathrm{C}\right)$ over longer periods of time $(1,2.5,3,4$, and 5.5 h).

The kaolin after calcinations at $1250{ }^{\circ} \mathrm{C}$ for $3 \mathrm{~h}$ is converted into mullite and free silica. This shows that silica has been removed from the support. Removal of this free silica causes the support porosity to increase from $24.3 \%$ to $49 \%$.

Fig. 5 shows XRD patterns of the mullite support (Fig. 5(a)) and the zeolite NaA membrane (Fig. 5(b)). The XRD pattern of $\mathrm{NaA}$ zeolite membrane confirms that zeolite NaA crystals were formed. In these two figures, the only phases, which can be observed, are zeolite NaA and mullite. Fig. 6 shows SEM photographs of the mullite support (Fig. 6(a)) and the zeolite NaA membrane (Fig. 6(b) and (c)). Porous structure of the support and thin layer of the membrane can be easily observed.

The membranes were evaluated in a PV setup as shown in Fig. 2. The synthesis procedure was also performed using different temperatures. As seen in Table 3, increasing crystallization temperature increases flux (samples 1, 2 and 3 ). In addition, it can be observed that there is no change in separation factor. This may be because at higher crystallization temperature, a thinner layer is formed. This is due to the fact that at higher temperatures, NaA zeolite crystals are smaller. This shows that these membranes have very high selectivity. The results show that a high temperature of $140{ }^{\circ} \mathrm{C}$ also results in zeolite $\mathrm{NaA}$ to be formed (sample 4). The crystallization temperature in a range of $70-140{ }^{\circ} \mathrm{C}$ was found to be very effective for making the $\mathrm{NaA}$ zeolite layer.

As mentioned, the synthesis procedure was performed using different times. As seen in Table 3, over a longer period of crystallization time flux decreased (samples 6 and 7). However, there is no change in separation factor. This behavior may be attributed to the fact that at over an extended period of crystallization time, a thicker membrane layer is formed, which causes flux to reduce. This shows that these membranes behave very high selective. It must be mentioned that 20400 is the highest measurable value using the GC at 90 wt. \% Ethanol concentration. In this work, any test (preparation membrane and PV test) carried out three times. The results show that short crystallization time $(1 \mathrm{~h})$ is not enough to make an effective zeolite layer on the support (sample 5). In addition, long crystallization time $(5.5 \mathrm{~h})$ causes $\mathrm{NaA}$ zeolite to transform to other zeolites such as NaX. As a result, this sample (8) shows poor selectivity. The crystallization time in a range of $2.5-4 \mathrm{~h}$ was found to be very effective for making the $\mathrm{NaA}$ zeolite layer.

The results confirm that zeolite membranes synthesized at $110{ }^{\circ} \mathrm{C}$ for $3 \mathrm{~h}$ via a single stage process can be recommended for dehydration of Ethanol/water mixtures.

\subsection{Water flux calculation using S.M. Correlation}

After water sorption experiments, Eq. (16) was employed to calculate diffusivity values of water through the zeolite matrix at $25{ }^{\circ} \mathrm{C}$ using water flux and sorption values at the same temperature. The diffusivity of pure water through the zeolite at $25{ }^{\circ} \mathrm{C}$ was computed (assuming $\mathrm{q}_{\mathrm{w}, \mathrm{p}}=0, \rho_{\mathrm{s}}=$ $1990 \mathrm{~kg} / \mathrm{m}^{3}, \varepsilon=0: 49$ and $\delta=30 \mu \mathrm{m}$ ) to be $3.11 \times 10^{-8} \mathrm{~cm}^{2} / \mathrm{s}$ (using experimental value of $\mathrm{J}_{\mathrm{w}}=0.22 \mathrm{~kg} / \mathrm{m}^{2} . \mathrm{h}$ and $\mathrm{q}_{\mathrm{w}, \mathrm{f}}=0.6$ $\mathrm{kg} / \mathrm{kg}$ zeolite at $25^{\circ} \mathrm{C}$ ). Sorption studies were also carried out using the zeolite NaA membrane. The zeolite membrane was crushed into fine pieces and the sorption experiments were performed in a similar manner as the powder. The sorption of the zeolite membrane was measured to be 0.29 $\mathrm{kg} / \mathrm{kg}$ zeolite again indicating that the membrane is highly hydrophilic. This value is lower than the values of water sorption for the zeolite powder because of the backing material. The results of water flux calculations are also presented in Table 4.

Comparison of experimental water fluxes and calculated water fluxes by S.M. Correlation are demonstrated in Table 4 and Fig. 7. Variation of the experimental flux through the zeolite membranes and the calculated flux with water concentration in the feed mixtures was shown. As seen in Table 4 and Fig. 7, reduction of water content in the mixture causes the water flux to decrease. A seen, the experimental and calculated data are consistent.

\subsection{FEM simulation results}

\subsubsection{Water concentration distribution}

Fig. 8 (a) and (b) illustrates surface water concentration distribution within two sub-domains of the membrane and feed, respectively. Ethanol/water solution containing 20 wt. \% Ethanol flows over the outer surface of the membrane module $(\mathrm{z}=0)$. Concentration profile within the feed side was measured by simultaneous solution of the continuity equations of mass and momentum using

\section{Kazemimoghadam et al.,}


COMSOL Multiphysics software version 5.2. FEM was applied by this software for numerical solution of the conservation equations. As observed, a concentration boundary layer is formed on the membrane-feed interface in feed compartment (Fig. 8 (b)). At $\mathrm{z}=0$, the water concentration is maximum (80 wt. \%). As the feed solution flows in the feed compartment, water moves towards the membrane surface due to the concentration and pressure differences (driving forces). Water concentration on the membrane surface is less than its value at the feed inlet (where water concentration is equal to its initial value, $\left.C_{0, w}\right)$. In fact, the water concentration on the membrane surface was calculated from the membrane selectivity (Eq. 29) and its value in the membrane side. Since water concentration in the membrane is always less than its value in the feed section, the water concentration on the membrane-feed boundary $\left(\mathrm{r}=\mathrm{R}_{2}\right)$ is always less than its value in the feed bulk.

Water transfer mechanism through the membrane was described only by diffusion. Since at the membranepermeate interface the vacuum condition was imposed, the water concentration on this boundary was measured to be zero (Fig. 8 (a)). Water distribution is highest on the membrane-feed interface, because it is obtained from its value in the feed part, which is always highest (Eq. (35)).

Fig. 9 represents the effect of various membrane lengths on the water concentration versus $r$-coordinate at constant temperature, flow rate and Ethanol initial concentration of $25{ }^{\circ} \mathrm{C}, 3 \mathrm{l} / \mathrm{min}$ and $20 \mathrm{wt}$ \%, respectively. Water concentration increases along $r$ direction, as expected. The concentration gradient in feed compartment (Fig. 9 (b)) is great at regions near the membrane-feed interface $\left(r=R_{2}\right)$ due to the mass transfer towards the membrane at this region (greater driving force). Concentration reaches a constant value $\left(\mathrm{C}_{0-\mathrm{w}}=80 \mathrm{wt} . \%\right)$ at radii more than $6.5 \mathrm{~mm}$. At regions near the feed entrance $(\mathrm{z}=30 \mathrm{~mm})$ total concentration is higher. This is because that this region is near the feed flow inlet with maximum concentration value $\left(\mathrm{C}_{0-\mathrm{w}}=80 \mathrm{wt}\right.$. \%). Water distribution within the membrane (Fig. 9 (a)) is linear. Its concentration is zero on the membrane-permeate boundary because of the dry membrane assumption applied on this boundary. This is due to the fact that the water is vaporized on this region and its concentration reaches zero. Water concentration is highest on feed-membrane interface, as mentioned above. Fig. 10 demonstrates the concentration profile along $\mathrm{z}$ coordinate at constant flow rate $(3 \mathrm{l} / \mathrm{min})$ and different radii. Results indicate that the variation of water concentration along the $\mathrm{z}$ coordinate is considerable and that cannot be neglected compared to its variation along $r$ coordinate. The figure also illustrates that the concentration value is greater at membrane module entrance, which is due to the higher water concentrations at feed inlet. By moving away from the membrane-feed interface within feed section ( $r>R_{2}$ in Fig. 10 (b)), the concentration increases. This behavior can be attributed to less water transfer towards the membrane at regions far from membrane-feed boundary, which will consequently result in much higher concentration values. Similarly, water distribution within the membrane (Fig. 10 (a))) is higher at areas near the feed-membrane interface $\left(R=R_{2}\right)$.

Figs. 11 and 12 show the effect of various feed flow rates on water concentration distribution within the feed and the membrane section. As can be seen, water concentration increases with growing feed flow rate. This behavior can be attributed to the fact that higher velocities (or flow rates) would decrease the contact time of the feed stream with membrane and consequently less water has enough time to pass through the membrane. Therefore, much higher concentrations will be obtained at feed compartment and at larger feed flow rates. Similarly, concentration profile grows in membrane segment (according to Eq. (35)). Hence, it can be concluded that the effective flow rate is 3 l/min.

Figs. 13 and 14 show the effect of Ethanol initial concentration in feed stream on water concentration. With increasing the initial Ethanol concentration, water concentration decreases, as expected. It can be concluded that the optimum Ethanol concentration is $1 \mathrm{wt} . \%$ at $25^{\circ} \mathrm{C}$. 4.3.2. Velocity distribution

Fig. 15 shows the velocity field in the feed phase of the PV membrane system. The velocity distribution was obtained using numerical solution of momentum balance. This was done by adding a "laminar flow" physic to the whole model in COMSOL. As can be seen from the figure, the velocity profile is fully developed after a short distance. Velocity is zero on the membrane-feed interface and the outer radius of feed section (due to no slip condition on these boundaries) and is highest on the half of the feed section boundary (symmetry condition).

Fig. 16 shows the effect of various membrane lengths on the velocity profile vs. radius in the feed sub-domain. According to the figure, the velocity profile is parabolic and becomes fully developed after a short distance (lengths approximately more than $18 \mathrm{~mm}$ ). As observed, entrance effects are considered in this simulation, which is one of the advantages of FEM simulation.

Fig. 17 represents the effect of varying feed flow rates on the velocity distribution vs. dimensionless length. Velocity profile is almost parabolic and reaches its maximum value at the regions close to the feed entrance. Maximum velocity magnitude increases with increasing feed flow rate, as expected.

\section{CONCLUSION}

Zeolite membranes have great potential for applications in Ethanol dehydration. Zeolite NaA membranes were synthesized on the porous mullite tubes by hydrothermal method. The best range operating condition (time and temperature) for hydrothermal synthesis of nanopore $\mathrm{NaA}$ zeolite membrane were $2.5-4 \mathrm{~h}$ and $70-140{ }^{\circ} \mathrm{C}$, respectively. The presented two models are comprehensive modeling approaches and give helpful insights into the actual transport process within nanoporous NaA membranes. PV separation of the zeolite NaA membranes was studied over a broad range of concentrations and temperatures for binary solvent-water systems. Very high water-solvent separation factors were obtained over the entire range of concentration for all Ethanol-water mixtures. High separation factors can be explained in terms of the strong

\section{Kazemimoghadam et al.,}


interaction between the water molecules and the ionic sites in the zeolite crystal lattice and the partial sieving achieved by the zeolite channels. In addition, the water flux through the membrane was found to be almost independent on the Ethanol concentration (at high water concentrations 80100 wt. \%), implying that the water transport through the membrane is uncoupled. The distinct advantages offered by inorganic zeolite membranes, are their high solvent resistance and no swelling tendency. Due to these properties, it is possible to use these membranes with a variety of solvents and over a broad spectrum of process conditions and temperatures. Thus, it is possible to use these membranes under conditions where the polymeric membranes cannot be used due to high swelling, membrane instability or low selectivity. By making zeolites with different cage sizes or different cationic species, it may be possible to tailor these membranes for specific purposes such as organic-organic separations and membrane reactor applications.

\section{REFERENCES}

[1]. Nour, M., Kosaka, H., Bady, M., Sato, S., Abdel-Rahman, K., 2017. Combustion and emission characteristics of Dl diesel engine fueled by ethanol injected into the exhaust manifold. Fuel Processing Technology, 164, 33-50.

[2]. Klinov, A., Akberov, A., Fazlyev, A., Farakhov, M., 2017. Experimental investigation and modeling through using the solution-diffusion concept of pervaporation dehydration of ethanol and isopropanol by ceramic membranes HybSi. Journal of Membrane Science, 524, 321-333.

[3]. Díaz, V., Tost, G., 2016. Butanol production from lignocellulose by simultaneous fermentation, saccharification, and pervaporation or vacuum evaporation. Bioresource Technology, 218,174-182.

[4]. Hoof, V., Dotremont, C., Buekenhoudt, A., 2006. Performance of Mitsui NaA type zeolite membranes for the dehydration of organic solvents in comparison with commercial Polymeric pervaporation membranes. Separation and Purification Technology, 48, 304-309.

[5]. Amnuaypanich, S., Patthana, J., Phinyocheep, P., 2009. Mixed matrix membranes prepared from natural rubber/poly(vinyl alcohol) semi- interpenetrating polymer network (NR/PVA semi-IPN) incorporating with zeolite $4 \mathrm{~A}$ for the pervaporation dehydration of water-ethanol mixtures. Chemical Engineering Science, 64, 4908 - 4918.

[6]. Sato, K., Sugimoto, K., Nakane, T., 2008. Preparation of higher flux $\mathrm{NaA}$ zeolite membrane on asymmetric porous support and permeation behavior at higher temperatures up to $145^{\circ} \mathrm{C}$ in vapor permeation. Journal of Membrane Science, 307, 181-195.

[7]. Li, Y., Chen, H., Liu, J., Li, H., Yang, W., 2007. Pervaporation and vapor permeation dehydration of Fischer-Tropsch mixed-alcohols by LTA zeolite membranes. Separation and Purification Technology, $57,140-146$.
[8]. Xia, L., Li, C., Wang, Y., 2016. In-situ crosslinked PVA/organosilica hybrid membranes for pervaporation separations. Journal of Membrane Science, 498, 263-275.

[9]. Li, Q., Cheng, L.,Shen, J., Shi, J., Chen, G., Zhao, J., 2017. Improved ethanol recovery through mixed-matrix membrane with hydrophobic MAF-6 as filler. Separation and Purification Technology, 178, 105112.

[10]. Yin, H., Lau, C., Rozowski, M., Howard, C., Xu, Y., Lai, T., Dose, M., 2017. Free-standing ZIF-71/PDMS nanocomposite membranes for the recovery of ethanol and 1-butanol from water through pervaporation. Journal of Membrane Science, 529, 286-292.

[11]. Narkkun, T., Jenwiriyakul, W., Amnuaypanich, S., 2017. Dehydration performance of double-network poly(vinyl alcohol) nanocomposite membranes (PVAs-DN). Journal of Membrane Science, 528, 284 295.

[12]. Jiang, J., Wang, L., Peng, L.,. Cai, C., Zhang, C., Wang, X., Gu, X., 2017. Preparation and characterization of high performance CHA zeolite membranes from clear solution. Journal of Membrane Science, 527, 51-59.

[13]. Santoro, S., Galiano, F., Jansen, C., Figoli, A., 2017. Strategy for scale-up of SBS pervaporation membranes for ethanol recovery from diluted aqueous solutions. Separation and Purification Technology, 176, 252-261.

[14]. Pera-Titus, M., Llorens, J., Tejero, J., Cunill, F., 2006. Description of the pervaporation dehydration performance of A-type zeolite membranes: A modeling approach based on the Maxwell-Stefan theory. Catalysis Today, 118, 73-84.

[15]. Yu, L., Zeng, C., Wang, C., Zhang, L., 2017. In situ impregnation-gelation-hydrothermal

crystallization synthesis of hollow fiber zeolite $\mathrm{NaA}$ membrane. Microporous and Mesoporous Materials, 244, 278-283.

[16]. Kondo, M., Kita, H., 2010. Permeation mechanism through zeolite $\mathrm{NaA}$ and T-type membranes for practical dehydration of organic solvents. Journal of Membrane Science, 361, 223-231.

[17]. Sorenson, S., Payzant, E., Gibbons, W., Soydas, B., Kita, H., Noble, R., Falconer, J.,2011. Influence of zeolite crystal expansion/contraction on $\mathrm{NaA}$ zeolite membrane Separations. Journal of Membrane Science, 366, 413-420.

[18]. Liu, Q., Jiang, Z., Cao, K., Nair, S., Cheng, X., Zhao, J., Gomaa, H., Wu, H., Pan, F., 2017. Pervaporation performance comparison of hybrid membranes filled with two-dimensional ZIF-L nanosheets and zero-dimensional ZIF-8 nanoparticles. Journal of Membrane Science, 523, 185-196.

[19]. Qu, H., Kong, Y., Lv, H., Zhang, Y., Yang, J., Shi, I., 2010. Effect of crosslinking on sorption, diffusion and pervaporation of gasoline components in hydroxyethyl cellulose membranes. Chemical Engineering Journal, 157, 60-66.

\section{Kazemimoghadam et al.,}


[20]. Lin, L., Zhang, Y., Kong, Y., 2009. Pervaporation separation of $n$-heptane-thiophene mixtures by polyethylene glycol membranes: Modeling and experimental. Journal of Colloid and Interface Science, 339, 152-159.

[21]. Das, P., Ray, S., 2013. Analysis of sorption and permeation of acetic acid-water mixtures through unfilled and filled blend membranes. Separation and Purification Technology, 116, 433-447.

[22]. Das, P., Ray, S., 2016. Pervaporation recovery of tetrahydrofuran from water with plasticized and filled polyvinylchloride membranes. Journal of Industrial and Engineering Chemistry, 34, 321-336.

[23]. Moulik, S., Kumar, K., Bohra, S., Sridhar, S., 2015. Pervaporation performance of PPO membranes in dehydration of highly hazardous $\mathrm{MMH}$ and UDMH liquid propellants. Journal of Hazardous Materials, 288, 69-79.

[24]. Samei, M., Iravaninia, M., Mohammadi, T., Asadi, A., 2016. Solution diffusion modeling of a composite PVA/fumed silica ceramic supported membrane. Chemical Engineering and Processing: Process Intensification, 109, 11-19.

[25]. Rezakazemi, M., Shahverdi, M., Shirazian, S., Mohammadi, T., Pak, A., 2011. CFD simulation of water removal from water/ethylene glycol mixtures by pervaporation. Chemical Engineering Journal, 168, 60-67.

[26]. Rom, A., Miltner, A., Wukovits, W., Friedl, A., 2016. Energy saving potential of hybrid membrane and distillation process in butanol purification: Experiments, modeling and simulation. Chemical Engineering and Processing, 104, 201-211.

[27]. Liu, D., Liu, G., Meng, L., Dong, Z., Huang, K., Jin, W.,2015. Hollow fiber modules with ceramicsupported PDMS composite membranes for pervaporation recovery of bio-butanol. Separation and Purification Technology, 146, 24-32.

[28]. Jain, M., Attarde, D., Gupta, S., 2017. Removal of thiophenes from FCC gasoline by using a hollow fiber pervaporation module: Modeling, validation and influence of module dimensions and flow directions. Chemical Engineering Journal, 308, 632648.

[29]. Moulik, S., Nazia, S., Vani, B., Sridhar, S., 2016. Pervaporation separation of acetic acid/water mixtures through sodium alginate/polyaniline polyion complex membrane. Separation and Purification Technology, 170, 30-39.

[30]. Qiao, Z., Wu, Y., Li, X., Zhou, J., 2011. Molecular simulation on the separation of water/ethanol azeotropic mixture by poly(vinyl alcohol) membrane. Fluid Phase Equilibria, 302, 14-20.

[31]. Hogendoom, A., van der Veen, J., van der Stegen, H., Kuipers, A., Versteeg, G.,2001. Application of the Maxwell-Stefan theory to the membrane electrolysis process Model development and simulations. Computers and Chemical Engineering, 25, 12511265.
[32]. Krishna, R., Paschek, D., 2002. Verification of the Maxwell-Stefan theory for diffusion of threecomponent mixtures in zeolites. Chemical Engineering Journal, 87, 1-9.

[33]. Pera-Titus, M., Llorens, J., Tejero, T., Cunill, F., 2006. Description of the pervaporation dehydration performance of A-type zeolite membranes: A modeling approach based on the Maxwell-Stefan theory. Catalysis Today, 118, 73-84.

[34]. Kazemimoghadam, M., Pak, A., Mohammadi, T., 2004. Dehydration of water/1-1-dimethylhydrazine mixtures by zeolite membranes. Microporous and Mesoprous Materials, 70, 127-134.

[35]. Speronello, K., 1986. Porous mullite. U.S. Patent No. 4628042.

[36]. Speronello, K., 1986. Porous mullite. U.S. Patent No 4601997.

[37]. Aguado, S., Gascón, J., Jansen, C., Kapteijn, F., 2009. Continuous synthesis of $\mathrm{NaA}$ zeolite membranes. Microporous and Mesoporous Materials, 120, 170176.

[38]. Malekpour, A., Millani, R., Kheirkhah, M., 2008. Synthesis and characterization of a $\mathrm{NaA}$ zeolite membrane and its applications for desalination of radioactive solutions. Desalination, 225, 199-208.

[39]. Sorenson, S., Payzant, A., Gibbons, W., Soydas, B., Kita, H., Noble, R., Falconer, J., 2011.Influence of zeolite crystal expansion/contraction on $\mathrm{NaA}$ zeolite membrane Separations. Journal of Membrane Science, 366, 413-420.

[40]. Bird, R., Stewart, W., Lightfoot, E., 1960.Transport phenomena, John Wiley \& Sons, New York, 2nd edition.

\section{Kazemimoghadam et al.,}

